\title{
DO DANO AMBIENTAL À CONSTRUÇÃO DE AMBIENTES SAUDÁVEIS: A UNIDADE DE ATENÇÃO AO IDOSO DO MUNICÍPIO DE UBERABA/MG
}

\author{
Luciana Cristina Caetano de Morais Silva ${ }^{1}$
}

Fernanda Rodrigues Carvalho de Paiva ${ }^{2}$

Jeferson David Almeida ${ }^{3}$

Mayra Hellena Ribeiro Torres ${ }^{4}$

RESUMO: Objetiva-se neste trabalho relatar a experiência de um grupo de alunos do primeiro período do Curso de Educação Física da Universidade Federal do Triângulo Mineiro. Ao selecionar a Unidade de Atenção do Idoso (UAI) no município de Uberaba para o desenvolvimento das atividades práticas da Disciplina Saúde e Sociedade, observou-se que a história da instituição escolhida se relaciona a um grave problema ambiental decorrente do descarrilamento do trem da Ferrovia Centro Atlântica. Após várias visitas ao local objetivando coletar informações sobre a história, infraestrutura e os serviços oferecidos aos idosos, os alunos puderam compreender a Unidade de Atenção ao Idoso como um ambiente saudável voltado especificamente para o atendimento das necessidades desse segmento. Os resultados demonstraram que a ampliação do espaço físico e dos serviços oferecidos foi possível face a mediação do Ministério Público local

1 Professora Adjunta do Departamento de Medicina Social da Universidade Federal do Triângulo Mineiro e responsável pela Disciplina Saúde e Sociedade do Curso de Educação Física no primeiro semestre/2010.

2 Acadêmica do primeiro período do Curso de Educação Física da UFTM.

3 Acadêmico do primeiro período do Curso de Educação Física de UFTM.

4 Acadêmica do primeiro período do Curso de Educação Física da UFTM. 
quando da proposição de um Termo de Ajustamento de Conduta entre a Ferrovia Centro Atlântica e a Prefeitura Municipal de Uberaba. A UAl oportuniza um ambiente saudável para a promoção da qualidade de vida dos idosos e consolida o compromisso para a concretização da cidadania. Conclui-se, portanto, que a mediação permitiu a concretização da intersetorialidade no planejamento e implantação de políticas públicas e ambientes saudáveis.

Palavras-chave: Problema Ambiental. Promoção de Saúde. Ambientes Saudáveis.

\section{INTRODUÇÃO}

O presente relato é fruto da experiência de um grupo de alunos do primeiro período do Curso de Educação Física da Universidade Federal do Triângulo Mineiro cujo objetivo era compreender de que maneira o educador físico poderia contribuir para a promoção de saúde de cidadãos da terceira idade. O desafio da proposta surgiu quando, ao selecionarem a Unidade de Atenção ao Idoso (UAI) no município de Uberaba para o desenvolvimento das atividades práticas da Disciplina Saúde e Sociedade, os alunos descobriram um ambiente saudável cujos pilares sobre a concepção de saúde e qualidade de vida do idoso superaram suas percepções enquanto alunos calouros de um curso de Educação Física. Concomitante, a origem daquele ambiente saudável estava diretamente relacionada à história de um grave problema ambiental ocorrido no município de Uberaba/MG, região do Triângulo Mineiro.

$\mathrm{Na}$ madrugada do dia 10/06/2003, uma composição com dezoito vagões da Ferrovia Centro Atlântica (FCA) transportando 381 toneladas de metanol, 245 toneladas de ectanol, 94 toneladas de isobutanol e 147 toneladas de cloreto de potássio, descarrilou promovendo a contaminação do córrego Alegria, afluente do rio Uberaba, local de captação de água do município mineiro. Além da contaminação da água, 42 mil metros quadrados de área preservada foram destruídos por um incêndio provocado pela explosão dos produtos químicos já que os mesmos eram inflamáveis. Pouco mais de uma semana, os habitantes do município de Uberaba ficaram sem água, sendo 0 
abastecimento realizado pela Ferrovia Centro Atlântica através da contratação de caminhões-pipas com atendimento prioritário aos hospitais, postos de saúde e escolas. (FERRARI, 2010, p. [on line])

A Constituição Federal no Capítulo VI defende o meio ambiente como um direito difuso e coletivo fundamental para a saúde da sociedade, cabendo ao agente infrator a reparação do dano causado, conforme pode ser observado artigo 225 , parágrafo $3^{\circ}$ da CF/88.

Art. 225. Todos têm direito ao meio ambiente ecologicamente equilibrado, bem de uso comum do povo e essencial à sadia qualidade de vida, impondo-se ao poder público e à coletividade o dever de defendê-lo e preservá-lo para as presentes e futuras instalações.

$[\ldots]$

Parág. $3^{\circ}$ As condutas e atividades consideradas lesivas ao meio ambiente sujeitarão aos infratores, pessoas físicas ou jurídicas, a sanções penais e administrativas, independentemente da obrigação de reparar os danos causados.

Quando o agente infrator causa um dano ambiental está diretamente causando dano a qualidade de vida e a saúde das coletividades. A Constituição Federal expressa a indissociabilidade entre homem e meio ambiente e, ainda, defende a concepção de meio ambiente enquanto um mecanismo primordial à saúde do homem tal qual preconizado na Carta de Ottawa.

As inextricáveis ligações entre a população e seu meio-ambiente constituem a base para uma abordagem socioecológica da saúde. O princípio geral orientador para o mundo, as nações, as regiões e até mesmo as comunidades é a necessidade de encorajar a ajuda recíproca - cada um a cuidar de si próprio, do outro, da comunidade e do meio-ambiente natural. A conservação dos recursos naturais do mundo deveria ser enfatizada como uma responsabilidade global.

$[\ldots]$

A proteção do meio-ambiente e a conservação dos recursos naturais devem fazer parte de qualquer estratégia de promoção da saúde. (CARTA DE OTTAWA, 2010, p. [on line]

Face a gravidade do problema ambiental desencadeado no município, o Ministério Público realizou um Termo de Ajustamento de Conduta (TAC) entre a Ferrovia Centro Atlântica e a Prefeitura Municipal. O TAC resultou na construção do espaço físico para a Unidade de Atenção ao Idoso (UAI), duas Unidades Regionais de Saúde (URS), a Casa do Adolescente, o Centro Social Urbano Elza Amui, uma Creche no bairro Residencial 2000, a construção de um poço artesiano, um veículo para o Instituto Estadual de Florestas, um caminhão para o Corpo de Bombeiros e investimentos ambientais no local do acidente por se tratar de área preservada. As obras e os veículos 
custaram R\$11,3 milhões a Ferrovia Centro Atlântica. (JORNAL DE UBERABA, 2010, p. [on line])

Criada pela Prefeitura Municipal de Uberaba/MG desde setembro de 1996, a Unidade de Atenção ao Idoso tem como proposta ser um espaço diferenciado voltado a terceira idade. Com o crescimento do número de usuários e das atividades desenvolvidas, o Termo de Ajustamento de Conduta realizado pelo Ministério Público entre a Ferrovia Centro Atlântica e a Prefeitura Municipal, possibilitou a criação da sede da UAI e a ampliação do espaço e dos serviços oferecidos para o atendimento aos idosos.

\section{OBJETIVO GERAL}

O presente relato de experiência tem como objetivo compreender a relação de intersetorialidade entre a Prefeitura Municipal de Uberaba/MG e a Promotoria de Justiça local para a elaboração, planejamento e execução de políticas públicas e ambientes saudáveis face ao problema ambiental gerado pelo descarrilamento do trem da Ferrovia Centro Atlântica no município.

\section{OBJETIVOS ESPECÍFICOS}

- Compreender o problema ambiental gerado pelo descarrilamento do trem da Ferrovia Centro Atlântica no córrego Alegria, afluente do Rio Uberaba, no Triângulo Mineiro;

- observar a participação da Ferrovia Centro Atlântica na construção da Unidade de Atenção ao Idoso (UAI);

- Identificar de que maneira o Ministério Público apresenta-se como um agente mediador para a construção de ambientes saudáveis, conforme observado na Declaração de Alma-Ata (1978) e da Carta de Ottawa (1986). 
- Caracterizar a Unidade de Atenção ao Idoso (UAI) enquanto um ambiente saudável o qual contribui para a promoção da saúde voltada à terceira idade aos cidadãos do município de Uberaba/MG;

- Refletir sobre o conceito ampliado de saúde promovido pelo Organização Mundial de Saúde (OMS) e ratificado no artigo 196 da Constituição Federal de 1988;

- Interrelacionar a Declaração de Alma-Ata e a Carta de Otawa ao artigo 225 (Do Meio Ambiente), parágrafo $3^{\circ}$ da Constituição Federal de 1988 na promoção de ambiente e políticas públicas saudáveis.

\section{METODOLOGIA}

Um grupo de alunos do primeiro período do Curso de Educação Física da Universidade Federal do Triângulo Mineiro selecionou a temática terceira idade para o desenvolvimento das atividades práticas da Disciplina Saúde e Sociedade, durante o primeiro semestre de 2010.

Para a execução da atividade foi realizado um cronograma dividido em três fases e a seleção da Unidade de Atenção ao Idoso (UAI) no município de Uberaba/MG para a realização das visitas.

Na primeira fase os alunos realizaram um levantamento bibliográfico sobre o tema com o objetivo de compreender o conceito terceira idade; a fisiologia na terceira idade; e os tipos de patologias mais recorrentes nesta fase da vida.

$\mathrm{Na}$ segunda fase os alunos realizaram três visitas à UAI. Na primeira visita os alunos puderam observar a relação entre a Ferrovia Centro Atlântica, a Promotoria de Justiça local e a Prefeitura Municipal de Uberaba/MG na criação da Unidade de Atenção ao Idoso. Observaram, ainda, a infra-estrutura da unidade e os tipos de serviços oferecidos aos idosos cadastrados na UAl e como os mesmos funcionavam.

$\mathrm{Na}$ terceira visita o grupo de alunos observou a relação dos idosos com os serviços promovidos pela unidade, bem como, puderam dialogar com os mesmos buscando compreender quais as atividades mais procuradas; suas percepções ao 
ambiente especificamente criado para atendimento de suas necessidades; e quais eram as suas sensações após o término de alguma atividade fosse ela física, mental, educacional ou de terapia ocupacional.

$\mathrm{Na}$ terceira visita os alunos voltaram à Unidade de Atenção ao Idoso com o objetivo de realizar entrevistas com os educadores físicos observando quais as modalidades e os exercícios físicos que melhor atendiam essa faixa etária. Observaram, também, quais as orientações sobre o cuidado ao corpo que os educadores físicos repassavam aos idosos visando proporcionar qualidade de vida e bem-estar.

$\mathrm{Na}$ terceira fase os alunos sistematizaram as informações obtidas durante as visitas à Unidade de Atenção ao Idoso promovendo uma reflexão com o conceito de ambiente e políticas públicas saudáveis definido pela Declaração de Alma-Ata (1978) e a Carta de Ottawa (1986).

\section{RESULTADOS}

A Unidade de Atenção ao Idoso é um projeto municipal criado para promover um ambiente de convivência social e comunitária, garantindo uma política social para a terceira idade (PEDROSA, 2004 apud MARTINS, 2007). Atualmente a UAI possui cerca de 10.000 pessoas cadastradas acima de 55 anos, sendo que em média 1.500 idosos frequentam por dia a unidade para o desenvolvimento de várias atividades como: ginástica; musculação; hidroginástica; natação; alongamento; relaxamento; Tai Chi Chuan; dança de salão; catira; forró; bateria; aulas de música; trabalhos manuais; fisioterapia; terapia ocupacional; aulas de alfabetização; aulas de informática; atendimento psicológico; assistência social e enfermagem.

Além da equipe multiprofissional para o desenvolvimento das atividades voltadas aos idosos, a UAI possui na sua estrutura organizacional uma coordenação geral e uma equipe de apoio administrativo, sendo esta responsável para 0 arquivamento e documentação; controle de material permanente e de consumo; e demais solicitações de natureza administrativa. A Unidade de Atenção ao Idoso é a principal referência para a 
população idosa em Uberaba contribuindo para a criação de vínculos de amizades, trocas de experiência, promoção da auto-estima, além da informação e lazer. (MARTINS, 2007)

A cada informação coletada durante as visitas à Unidade de Atenção ao Idoso, os alunos puderam compreender a saúde como resultado de um bem-estar bio-psico-social e não meramente apenas como ausência de doenças. As atividades desenvolvidas pelos idosos, bem como, a qualidade de vida proporcionada por aquele espaço aos cidadãos da terceira idade fazem da Unidade de Atenção do Idoso um ambiente saudável fruto de uma política pública saudável protagonizada pelo Ministério Público quando da elaboração do Termo de Ajustamento de Conduta entre a Ferrovia Centro Atlântica e a Prefeitura Municipal de Uberaba.

A Declaração de Alma-Ata e a Carta de Ottawa são documentos internacionais fundamentais que influenciaram o Movimento de Reforma Sanitária no Brasil. Resposta às reformas liberais do final dos anos 70 e início dos 80 e da crise dos paradigmas para a compreensão do processo saúde-doença, a Declaração de Alma-Ata defende uma concepção ampliada de saúde enquanto:

estado de completo bem- estar físico, mental e social, e não simplesmente a ausência de doença ou enfermidade - é um direito humano fundamental, e que a consecução do mais alto nível possível de saúde é a mais importante meta social mundial, cuja realização requer a ação de muitos outros setores sociais e econômicos, além do setor saúde. (DECLARAÇÃO DE ALMA-ATA, 2010, p. [on line])

A promoção de saúde nos termos defendidos em Alma-Ata não são restritivos ao setor da saúde. Ao contrário, a concepção ampliada de saúde exige para sua efetivação a mobilização e a co-responsabilidade de outros setores para o planejamento de ações de saúde que atendam as necessidades das coletividades.

A saúde é o maior recurso para o desenvolvimento social, econômico e pessoal, assim como uma importante dimensão da qualidade de vida. Fatores políticos, econômicos, sociais, culturais, ambientais, comportamentais e biológicos podem tanto favorecer como prejudicar a saúde. As ações de promoção da saúde objetivam, através da defesa da saúde, fazer com que as condições descritas sejam cada vez mais favoráveis. (CARTA DE OTTAWA, 2010, p. [on line])

A intersetorialidade é uma estratégia fundamental para a promoção de saúde, pois, "[...] os pré-requisitos e perspectivas para a saúde não são assegurados somente 
pelo setor saúde. Mais importante, a promoção da saúde demanda uma ação coordenada entre todas as partes envolvidas: governo, setor saúde e outros setores sociais e econômicos, organizações voluntárias e não-governamentais, autoridades locais, indústria e mídia" (CARTA DE OTTAWA, 2010, p. [on line]).

Embora a Unidade de Atenção ao Idoso já existisse antes do Termo de Ajustamento de Conduta, a mediação do Ministério Público ao cobrar reparação do dano ambiental causado aos munícipes de Uberaba/MG, colaborou para a criação de políticas públicas saudáveis ao passo que colocou a saúde na agenda de prioridades dos políticos e demais dirigentes de outros setores para decidirem como e de que forma o dano poderia ser reparado pelo agente infrator.

\section{CONSIDERAÇÕES FINAIS (200)}

As visitas à Unidade de Atenção ao Idoso realizadas oportunizaram a compreensão de que o conceito de saúde está além das condições meramente biológicas, indicando a complexidade da promoção de saúde e da qualidade de vida do idoso. Nesse sentido, o meio ambiente ecologicamente equilibrado, conforme disposto no artigo 225 da Constituição Federal de 1988, constitui estratégia fundamental para a promoção de saúde e qualquer ação que por ventura venha prejudicar o meio ambiente constitui violabilidade do direito à saúde.

A mediação do Ministério Público, além do cumprimento da exigência legal da reparação do dano, demonstrou a importância de outros setores se co-responsabilizarem pela gestão da saúde de uma coletividade. A co-responsabilização permitiu a criação de ambientes saudáveis como pode ser observado na Unidade de Atenção ao Idoso do município de Uberaba/MG.

Entende-se, portanto, a intersetorialidade enquanto uma estratégia essencial para a elaboração de políticas públicas saudáveis e de ambientes saudáveis capaz de possibilitar ações de saúde de modo a atender as necessidades de uma coletividade. 


\section{REFERÊNCIAS}

BRASIL. Constituição da República Federativa do Brasil: promulgada em 05 de outubro de 1988. Disponível em: http://www.senado.gov.br/legislacao/const Data de acesso: 11 jul. 2010.

CARTA DE OTTAWA. Primeira Conferência Internacional sobre Promoção de Saúde. Otawa, 1986. Disponível em: http://www.opas.org.br/coletiva/uploadarq.pdf Data de acesso: 09 jul. 2010.

DECLARAÇÃO DE ALMA-ATA. Conferência Internacional sobre Cuidados Primários em Saúde. Alma-Ata/URSS, $1978 . \quad$ Disponível em: http://opas.org.br/coletiva/uploAdarq/Alma-Ata.pdf Data de acesso: 09 jul. 2010.

FERRARI, Eduardo. Sem água, Uberaba decreta estado de calamidade pública. 11/06/2003. Disponível em: http://noticias.uol.com.br/inter/reuters/2003/06/11/ult27u36141.jhtm Data de acesso: 01 jul. 2010.

JORNAL UBERABA. Marcos Montes diz que acidente de trem desencadeou corrente de solidariedade. Jornal de Uberaba, Caderno Política, 23 ago. 2006. Disponível em: http://www.jornaldeuberaba.com.br/?MENU=CadernoA\&SUBMENU=Política\&CODIGO=8 337 Data de acesso: 01 jul. 2010.

MARTINS, Marília Gonçalves. Estilo de Vida \& Promoção da Saúde: estudo da Unidade de Atenção ao Idoso (Uberaba/MG). 2007. 78f. Trabalho de Conclusão de Curso. (Bacharelado em Enfermagem) - Curso de Enfermagem, Universidade de Uberaba, Uberaba/MG. 